\title{
Jan van Eyck Grisallas. Madrid: Fundación Colección Thyssen-Bornemisza
}

Delmira Espada

\section{(2) OpenEdition}

\section{Journals}

\section{Edição electrónica}

URL: http://journals.openedition.org/medievalista/469

DOI: 10.4000/medievalista.469

ISSN: 1646-740X

\section{Editora}

Instituto de Estudos Medievais - FCSH-UNL

\section{Refêrencia eletrónica}

Delmira Espada, « Jan van Eyck Grisallas. Madrid: Fundación Colección Thyssen-Bornemisza », Medievalista [Online], 8 | 2010, posto online no dia 01 dezembro 2010, consultado o 22 setembro 2020. URL : http://journals.openedition.org/medievalista/469; DOI : https://doi.org/10.4000/medievalista 469

\section{(c) $(1)(9$}

Mediavalista está licenciado com uma Licença Creative Commons - Atribuição-NãoComercial 4.0 Internacional 
Titulo: Recensão

Jan van Eyck Grisallas. Madrid: Fundación Colección Thyssen-

Bornemisza, 2009.

Autor(es): Delmira Espada

Enquadramento Institucional: Membro do IEM, Faculdade de Ciências Sociais

e Humanas, Universidade Nova de Lisboa

Contacto: delmiraespada@gmail.com

Fonte: Medievalista [Em linha]. №8, (Julho 2010). Direc. José Mattoso. Lisboa: IEM.

Disponível em: http://www2.fcsh.unl.pt/iem/medievalista/

ISSN: 1646-740X

\section{Recensão}

\section{Jan van Eyck Grisallas. Madrid: Fundación Colección}

Thyssen-Bornemisza, 2009

\section{Delmira Espada}

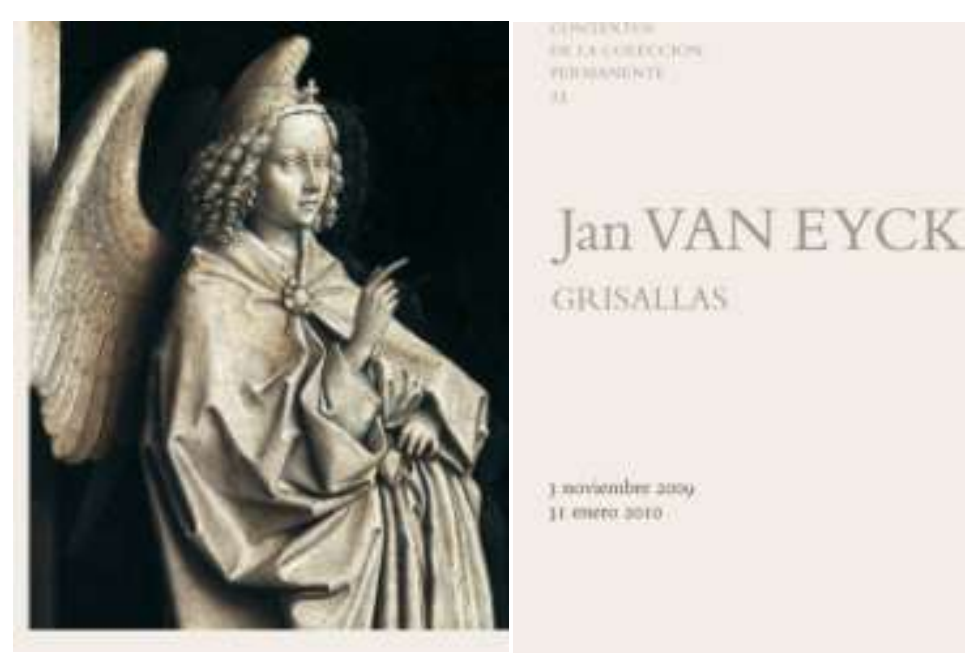


O presente catálogo assinala a exposição realizada no Museu Thyssen-Bornemisza, em Madrid, de 3 de Novembro de 2009 a 31 de Janeiro de 2010. Comissariada por TillHolger Borchert, a mostra integra-se num conceito de exposição que este museu tem vindo a desenvolver, visando o estudo aprofundado de algumas peças do acervo. Esta série de exposições intituladas "Contextos de la Colección Permanente" consiste num novo olhar sobre uma peça da colecção da instituição, em torno da qual se desenvolve a linha orientadora do certame. O Díptico da Anunciação de Van Eyck foi o mote para a iniciativa e para um conjunto de estudos que procuram reflectir sobre a produção em grisalha. A exposição integrava um conjunto de diversas peças, executadas ou influenciadas por esta técnica pictórica, nas diferentes modalidades de representação: manuscritos iluminados, pequenas esculturas esculpidas em marfim ou alabastro, pinturas sobre madeira, desenhos e têxteis.

O catálogo comporta quatro estudos, da autoria de Till-Holger Borchert, Julien Chapuis, Melanie Holcomb e Alexander Markschies, que funcionam como extensão reflexiva da própria exposição. Apresentam abordagens distintas, relacionadas entre si e com a produção de obras em grisalha. Por último, inclui ainda o catálogo propriamente dito, com as dezoito peças seleccionadas e acompanhadas por textos da autoria do comissário, situando as obras escolhidas. Do ponto de vista estrutural, esta publicação revela uma boa organização: os textos iniciais oferecem propostas de leitura que visam o entendimento da grisalha, nas suas diversas modalidades, num período temporal bastante alargado e com boa selecção de imagens; o catálogo final fornece informação detalhada, actualizada e contextualizante das obras evocadas a propósito do Díptico da Anunciação.

Para além das peças oriundas do próprio Museu e da Biblioteca Nacional de Espanha, contou ainda com obras de vários museus alemães, austríacos, belgas, norte americanos, franceses, italianos e holandeses. Neste âmbito tão alargado há a lamentar a ausência de qualquer representação portuguesa. Quando se justificaria, por exemplo, a presença do iluminado 165, da Biblioteca Nacional de Portugal, que teria fornecido o pretexto ideal para a introdução de Guillaume Vrelant, um dos artistas responsáveis pelo renascimento da iluminura em grisalha nos Países Baixos e ao qual o catálogo, praticamente, não faz referência. Guillaume Vrelant marcou uma linguagem pictórica muito particular, no 
domínio da iluminura em grisalha, bastante difundida durante o século XV e com ligações interessantes não só às cortes francesa e borgonhesa, como também com fortes influências que se estenderam à Península Ibérica. A referida ausência poder-se-á justificar, talvez, pela coincidência temporal desta mostra com a exposição lisboeta dos 500 anos da fundação do Mosteiro da Madre de Deus, no Museu Nacional do Azulejo, que contou com a presença inevitável do manuscrito. Mas em sua substituição, poderse-ia pensar também no LA 133, um Breviário Franciscano da primeira metade do século XIV, pertencente à Fundação Calouste Gulbenkian, ou ainda no LA 137, um Livro de Horas da mesma Fundação que, em nossa opinião, representaria melhor a miniatura holandesa do que o exemplar apresentado, em Madrid, um Livro de Horas proveniente do Koninklijke Bibliotheek, de Haia (Cat. 10).

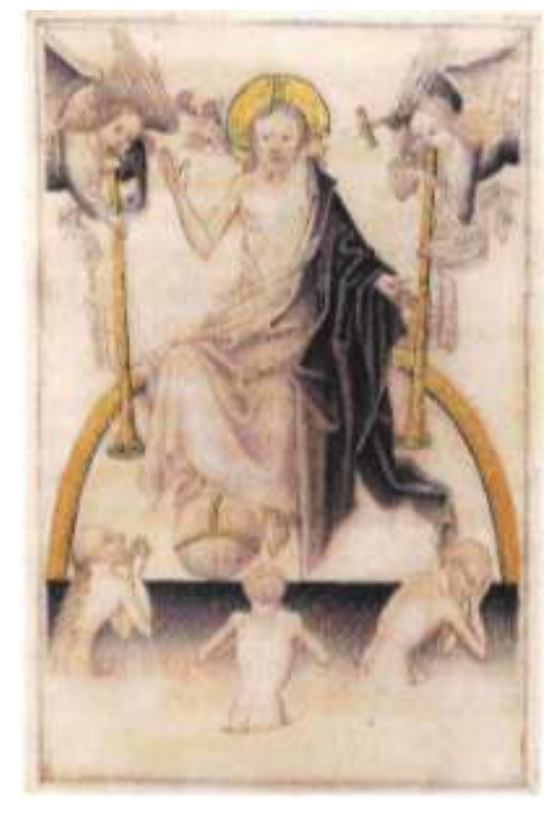

FCG, LA 137, fl.167v

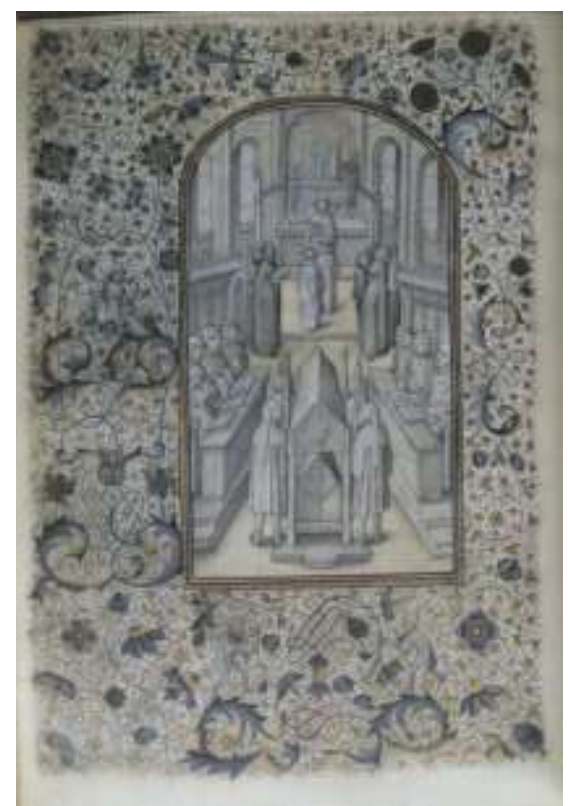

Guillaume Vrelant, BNP, IL165, fl. 72v

O Díptico da Anunciação integra-se num dos eixos fundamentais do entendimento da grisalha: a pintura flamenga sobre painéis de madeira, da primeira geração dos primitivos flamengos, constituindo exemplo de excelência e um marco da qualidade que este género de pintura atingiu. A pintura em grisalha sobre madeira foi muito difundida nos Países Baixos, durante os séculos XIV e XV, assinalando presença constante no exterior dos volantes dos retábulos. Procurando simular de forma ilusória a escultura em 
cor de pedra, é um ponto incontornável no entendimento da utilização da grisalha, enquanto meio de expressão artística. Alguns autores viram nesta renúncia da cor, que está subjacente à técnica da grisalha, razões ascéticas ou uma adequação à liturgia cristã durante o período de penitência da Quaresma. Esta relação da produção artística com as práticas religiosas não é, pelo menos segundo as teorias mais recentes, a principal razão que justifica o gosto e a difusão da referida técnica durante os séculos XIV e XV, fundamentando-a antes no interior do campo artístico. Rudolf Preimesbergue defende que a pintura ilusionista dos primitivos flamengos terá sido o resultado de uma competição entre a pintura e a escultura.

A questão da simulação de uma escultura em pedra, sem policromia, é um tema fascinante que merece discussão mais alargada. Em primeiro lugar, parece-nos inquestionável que há, nas obras da primeira geração dos primitivos flamengos, uma tentativa de reprodução de peças escultóricas sem policromia. Essa situação torna-se particularmente evidente na Anunciação das portadas exteriores do Altar do Juízo Final, de Rogier van der Weyden, onde o pintor vai ao ponto de reproduzir os apoios características da escultura; ou, na forma como combina, num mesmo retábulo, a figuração dos doadores policromos e a simulação de esculturas em grisalha. Esta intenção de simulação de um medium diferente é talvez o ponto mais interessante que o tema das grisalhas pode trazer para a discussão. Com a segunda geração de mestres flamengos a grisalha conheceu, em parte, uma pequena alteração na forma como é utilizada, servindo agora essencialmente para representar todo o género de núcleos escultóricos. Contudo, tal utilização na representação do trabalho em pedra perde o carácter ilusório que a primeira geração dos primitivos havia desenvolvido.

Duas questões transversais às reflexões trazidas pelo catálogo se levantam a propósito destas formulações de núcleos escultóricos em color lapidum. Por um lado, a questão de fundo, que não se esgota nos estudos aqui publicados e que se prende com a policromia das esculturas: se durante a Idade Média a grande maioria da escultura era policroma, porque motivo a pintura e a iluminura coevas a representam quase exclusivamente em cor de pedra? Sobre isto, uma possível justificação é aflorada por Julien Chapius, que no seu texto desenvolve uma abordagem específica da policromia parcial das esculturas e das razões que justificam a ausência total ou parcial da cor. É que, em sua opinião, 
houve sempre uma produção equilibrada de peças policromas e não policromas, o que sugere todo um caminho ainda a percorrer pela investigação.

Por outro lado, há a considerar também os motivos que estiveram na origem do desenvolvimento das representações em grisalha. Os autores são unânimes em sublinhar o reflexo da disputa entre pintores e escultores, que levou a um virtuosismo técnico cada vez mais apurado. Foi, segundo eles, a demonstração de uma capacidade técnica que, ao colocar a pintura num patamar superior ao da escultura, impulsionou o desenvolvimento da grisalha nos painéis de madeira. Agregada a esta ideia de virtuosismo, os autores vêem ainda nesta renúncia da cor um aumento do grau de dificuldade a que os pintores se sujeitaram, para evidenciar a sua mestria. Melanie Holcomb, mostra mesmo como a grisalha foi uma técnica que se prestava a revelar o virtuosismo do artista, no quadro desta disputa entre pintores e escultores. A autora sublinha que, ao abdicar conscientemente da cor, a grisalha requeria uma grande habilidade, assinalando também o conceito de artifício que está subjacente a este género. Além do duplo prazer que estas representações suscitam: o prazer que o artista sente pela mestria com que executa a imagem ilusória de uma escultura e a admiração que esta provoca em quem a observa.

Tal como Till-Holger Borchert, comissário da exposição, Melanie Holcomb partilha a opinião de que a renúncia à cor é uma dificuldade acrescida a que os pintores se sujeitaram. Em nossa opinião, trata-se porém de uma falsa questão. Parece-nos bastante credível que tenha sido a rivalidade entre pintores e escultores a responsável pelo desenvolvimento de uma técnica cada vez mais apurada, não sendo aceitável entender a utilização da grisalha como um aumento do grau de dificuldade. Pelo contrário, o seu uso é a forma mais eficaz de atingir o fim pretendido - a ilusão de estarmos perante uma escultura. Esta dúvida, que os primitivos flamengos pretenderam criar no espírito dos espectadores jamais seria possível por meio de representações policromas. A representação de uma escultura policroma dificilmente causaria o efeito ilusório de estarmos perante o objecto autêntico. 


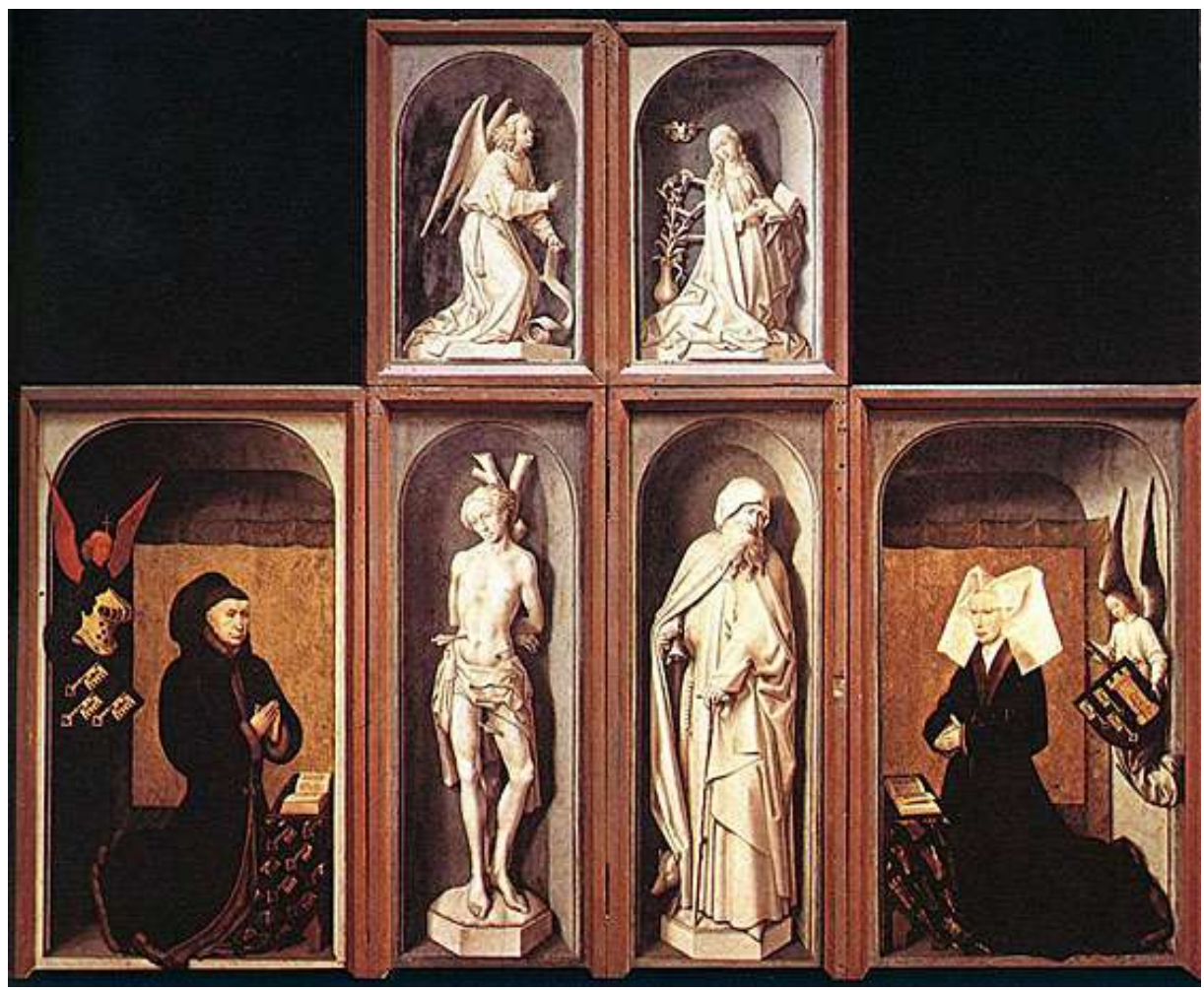

Rogier van der Weyden, Alas exteriores do Altar do Juízo Final, c. 1450. Beaune, Musée Hotel-Dieu

Já a iluminação de manuscritos em grisalha assenta em pressupostos diferentes. Em primeiro lugar, há que avaliar a relação entre algumas manuscritos iluminados e o gosto por uma estética linear, mais próxima do desenho. Melanie Holcomb trata desta relação subtil entre o desenho e a grisalha, assinalando como o gosto por uma estética de carácter gráfico, muitas vezes realçada pela introdução de fundos cromáticos, conduziu a obras de excepção. É o caso do bem conhecido Livro de Horas de Jeanne d'Evreux e de todo o conjunto de trabalhos que aí foram beber a sua inspiração. A leitura que a autora faz desta obra condensa em si mesma o que foi a utilização da grisalha no âmbito da iluminura - uma ferramenta que o iluminador usou para obter efeitos visuais, sem necessidade de se servir de materiais dispendiosos. Embora possamos encontrar alguns exemplos de iluminuras com grisalhas para reproduzir interiores de pedra ou esculturas de vulto, de uma maneira geral os manuscritos iluminados utilizam a grisalha como recurso expressivo, sendo os seus resultados plasticamente muito variados.

Acresce, ainda, o facto de a presença da grisalha em manuscritos iluminados e a sua grande difusão na segunda metade do século XIV estar directamente relacionada com o 
gosto particular da casa real francesa. O seu expoente máximo foi o já citado Livro de Horas de Jeanne d'Evreux, iluminado por Jean de Pucelle e encomendado pelo futuro rei de França, Carlos V. A corte francesa foi a grande responsável pela crescente popularidade da grisalha durante a segunda metade do século XIV. As miniaturas deste manuscrito, como diz Melanie Holcomb, citando Barbara Bohem, não têm o mais pequeno detalhe em ouro ou prata, como seria de esperar numa encomenda régia. A sua extraordinária beleza deve-se à capacidade do iluminador e à sábia articulação conseguida entre as figuras em grisalha e a introdução pontual da cor. Este manuscrito teve uma influência bastante significativa nas obras produzidas depois, salientando-se pela sua importância o Frontal de Narbona e a Mitra do Museu de Cluny, ambas atribuídas a Jean de Orléans. Influência que se fez igualmente sentir noutros manuscritos iluminados, como o Livro de Horas de Bruxelas e o Saltério de Jean de Berry, atribuídos a André Beauneveau, ou o Saltério de Bonne do Luxemburgo de Jean le Noir.

Como Pierre Cockshaw já havia assinalado, a propósito da exposição da Bibliotheque Royale Albert $\mathrm{I}^{\mathrm{er}}$, em 1986, a iluminura em grisalha, após o seu período áureo sob o mecenato da corte francesa, conhece em meados do século XV um renascimento nos Países Baixos, centrado na corte borgonhesa. Dreux Jean, Jean le Tavernier, Guillaume Vrelant e Simon Marmion, ao serviço de Filipe o Bom e de seu filho Carlos o Temerário, foram os principais responsáveis por esse renascimento.

Para concluir esta breve passagem pelas reflexões sobre o Díptico da Anunciação, regressemos às duas pequenas tábuas, onde as figuras alvas contrastam com um fundo negro polido. Esta elaborada construção pictórica procurou simular uma peça escultórica. Para o conseguir, Jan van Eyck, deitou mão de todos os artifícios de que a pintura dispunha: os pedestais, onde assentam as figuras, ultrapassam o limite dos nichos, sobrepondo-se mesmo à moldura; ampliou o efeito ilusório pela representação de sombras projectadas sobre a moldura e os reflexos que as figuras projectam no fundo negro polido; para aumentar a verosimilhança da moldura de pedra inscreveu nela o texto, que geralmente acompanha esta cena, como se estivesse cinzelado. Por último, recorre à grisalha maximizando os valores lumínicos e com isso a simulação mais eficaz da tridimensionalidade. De que resulta uma maior aproximação ao carácter inanimado da representação escultórica, ampliando a possibilidade de ilusão. Como assinalou 
Julien Chapuis, Jan van Eyck evoca, no fundo negro onde faz reflectir as figuras, soluções plásticas exploradas por outras modalidades artísticas, tais como o Grande Camafeu de França, datado de cerca de 23 d. C. ou uma escultura em mármore, sem policromia, com a Fuga para o Egipto, datada de 1325-1350 e cujas figuras brancas também contrastam com uma pedra negra brilhante. A própria moldura avermelhada alude ao pórfiro egípcio, obrigando-nos a repensar o seu valor simbólico.

No essencial, este catálogo constitui, pois, um bom contributo e um excelente instrumento para o entendimento da grisalha nas suas várias modalidades. Reúne, num único volume, um conjunto alargado de obras e de reflexões sobre esta técnica pictórica, que abarca um conjunto vasto de manifestações artísticas. Apresenta ainda um extenso repertório bibliográfico, bastante actualizado, ao qual talvez se devesse juntar as publicações de Lynette Bosch, sobre o iluminador castelhano Juan de Carrión, pela influência que no seu trabalho exerceu a iluminura dos Países Baixos. Disponível na versão on-line, a exposição pode ser virtualmente visitada em http://www.museothyssen.org/microsites/exposiciones/2009/Van-Eyck/vv/index.htm.

De 27 de Novembro de 2010 a 20 de Março de 2011, estará patente ao público na Sttatsgalerie em Estugarda, outra realização análoga, centrada nos doze painéis de madeira da Paixão em grisalha de Hans Holbein, o Velho, recentemente restaurados, o que certamente trará novas possibilidades de estudo sobre esta temática, em especial no mundo germânico.
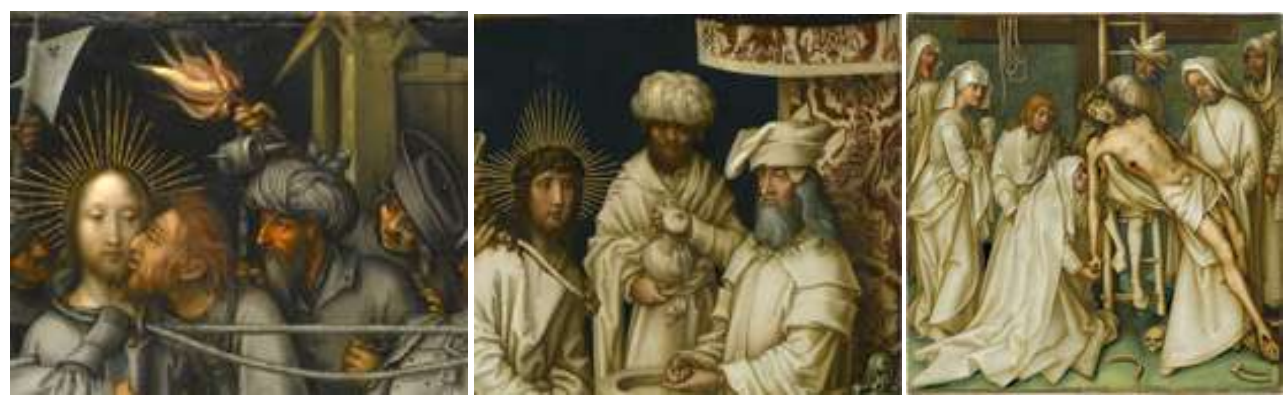

Pormenores dos painéis da Paixão em grisalha de Hans Holbein, o Velho. 


\section{COMO CITAR ESTE ARTIGO}

\section{Referência electrónica:}

ESPADA, Delmira - Recensão. Jan van Eyck Grisallas. Madrid: Fundación

Colección Thyssen-Bornemisza, 2009. Medievalista [Em linha]. Nº 8 , (Julho de 2010).

[Consultado dd.mm.aaaa]. Disponível em

http://www2.fcsh.unl.pt/iem/medievalista/MEDIEVALISTA8lespada8010.html.

ISSN 1646-740X.

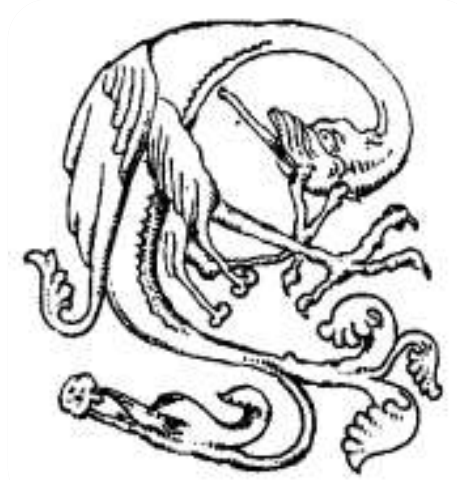

